\title{
Gulf Coast parents speak: children's health in the aftermath of the Deepwater Horizon oil spill
}

Jaishree Beedasy , Elisaveta P. Petkova , Stephanie Lackner \& Jonathan Sury

To cite this article: Jaishree Beedasy, Elisaveta P. Petkova , Stephanie Lackner \& Jonathan Sury (2020): Gulf Coast parents speak: children's health in the aftermath of the Deepwater Horizon oil spill, Environmental Hazards, DOI: 10.1080/17477891.2020.1772188

To link to this article: https://doi.org/10.1080/17477891.2020.1772188

曲 Published online: 16 Jun 2020.

Submit your article to this journal ¿

Џll Article views: 6

Q View related articles $\llbracket$

View Crossmark data 4 


\title{
Gulf Coast parents speak: children's health in the aftermath of the Deepwater Horizon oil spill
}

\author{
Jaishree Beedasy ${ }^{a}$, Elisaveta P. Petkova ${ }^{b}$, Stephanie Lackner ${ }^{c}$ and Jonathan Sury ${ }^{a}$ \\ ${ }^{a}$ National Center for Disaster Preparedness, The Earth Institute, Columbia University, New York, NY, USA; \\ ${ }^{b}$ Department of Earth and Environmental Sciences, Columbia University, New York, NY, USA; ${ }^{C}$ IE School of \\ Global and Public Affairs, IE University, Madrid, Spain
}

\begin{abstract}
This paper examines the physical and mental health of children following the Deepwater Horizon oil spill (DHOS). A multi-stage sampling design was used to select households for inclusion in the study. Data were obtained from parental interviews $(n=720)$ in the harder-hit areas of Louisiana in the US Gulf Coast. Three out of five parents reported that their child had experienced physical health symptoms and nearly one third reported that their child had mental health issues since the oil spill. Both direct physical exposure and indirect economic exposure were found to be predictors of physical and mental health issues among the children. Our findings contribute to bridge the research gap on the impacts of the direct and indirect exposures of the DHOS on the health of children. The study underscores the importance of understanding the health and recovery trajectories of children and youth exposed to disasters. Knowledge gained from this study together with the emerging literature on the effect of the oil spill disaster on children can contribute towards more evidence-based public health policies and enhance the recovery of children and their families in the aftermath of disasters.
\end{abstract}

\section{ARTICLE HISTORY}

Received 3 October 2019

Accepted 11 May 2020

\section{KEYWORDS}

Exposure; disaster; children; health; oil spill

\section{Introduction}

The U.S. Gulf Coast was still recovering from the impacts of major hurricanes when the Deepwater Horizon oil rig exploded on April 20, 2010. The resulting spill was one of the largest marine oil spills in history and was unparalleled in its duration, mode of oil release and complexity (Goldstein et al., 2011; Palinkas, 2012). The spill had and continues to have profound social, economic, health and environmental impacts on the Gulf Coast. This region is particularly vulnerable to disasters triggered by natural hazards and to technological disasters due to its geographical location and concentration of oil and gas industry and infrastructure. The region's vulnerability is further compounded by poor health metrics such as high obesity and diabetes rates, and by socio-economic factors such as chronic poverty and a struggling economy (Arosemena et al., 2013; Goldstein et al., 2011). While disasters do not discriminate who they affect, they disproportionately impact the most vulnerable groups in society (Petkova et al., 2017). Children are particularly vulnerable during disasters due to their physical characteristics, their widely varying stages 
of development and their reliance on adults for their safety and well-being (Chrisman \& Dougherty, 2014). A growing body of evidence demonstrates that exposure to disasters is associated with severe and long lasting health impacts among children and adolescents (Chrisman \& Dougherty, 2014; Kousky, 2016; Masten \& Narayan, 2012). To date there are few reports on the impact of the Deepwater Horizon oil spill on children's health (Murray, 2011; Osofsky et al., 2016). This paper aims to shed some light on this important, and yet relatively understudied area. We conducted a household survey in regions that were impacted by the Deepwater Horizon oil spill (DHOS) to collect previously unavailable data on exposure, child health, and household recovery. The paper describes the study design and presents the analysis and study findings on the relationship between exposure and children's health outcomes. We conclude with a discussion of the findings, implications for practice and future research to address children's health issues for long term recovery.

\subsection{Deepwater Horizon oil spill}

Following the explosion of the Deepwater Horizon rig off the coast of Louisiana, the Macondo well released an estimated 4.9 million barrels of crude oil prior to capping (DOI, 2010). The explosion caused the death of 11 workers and injured 17. Furthermore, the oil spill has had devastating impacts on the health and well-being of local communities, the environment, and the economy. One notable dimension of technological disasters such as the DHOS is that their consequences emerge slowly and persist over long periods of time in contrast to rapid-onset technological disasters having a sudden onset or a short duration such as a bridge collapse (Cline et al., 2010; Freudenburg, 1997). The longer exposure duration to the oil spill is more likely to result in a prolonged period of acute stress (Palinkas, 2012). To understand its impacts, the DHOS has been compared with the 1989 Exxon Valdez oil spill (EVOS) in Alaska, the second largest in US waters after the DHOS (Gill et al., 2012; Ritchie et al., 2011). Similar to the communities affected by the EVOS, a great proportion of the communities living in the Gulf of Mexico area depend on natural resources for their social, cultural, and economic existence (Ritchie et al., 2011). According to studies in the aftermath of the EVOS, individuals highly impacted by the EVOS reported negative health outcomes such as anxiety, stress and depression (Palinkas et al., 1992, 1993). Adults reported adverse effects associated with household exposure to the EVOS on children's behaviour, including a deterioration in relations with other children in the community, decline in grades in school, and difficulties getting along with parents and siblings (Mclees-Palinkas, 1994). These findings are helpful in informing studies examining DHOS to prevent and mitigate such events. It is necessary to understand this specific DHOS disaster and its impacts on the affected communities in the Gulf Coast. Yet, there are very few studies that have examined the impact of oil spills on children (Murray, 2011; Osofsky et al., 2016).

\subsection{Exposure to the oil spill and children's health}

Disasters can exert profound and enduring effects on children and youth. Physical and mental health distress can be caused by a series of cascading stressors set into motion by the disaster. Primary stressors associated with disasters can result from direct exposure to the forces of harm e.g. explosions, strong winds, flooding, chemicals, or 
toxic substances (Chrisman \& Dougherty, 2014; Lock et al., 2012; Shultz et al., 2007). During an oil spill disaster, direct or primary exposure can be through dermal contact, inhalation or ingestion of oil, tar or dispersant (Goldstein et al., 2011; Institute of Medicine, 2010). Secondary or indirect exposure can happen when an individual e.g. the child or youth, is not directly exposed to the event but is exposed to an impacted entity (e.g. individual, family) or an ecosystem (e.g. community, environment). Secondary exposures are longer term, such as disruption of daily routines and activities, having family and loved ones experience anxiety, distress or income loss, or having to relocate (Lock et al., 2012; Shaw et al., 2012). The associated secondary stressors can cause mental distress and can further exacerbate the effects of the primary stressors (Lock et al., 2012). In the aftermath of an oil spill, secondary exposure and associated secondary stressors can arise, for example, from a family member's health being directly affected by toxic material, family members losing a job or income, the household not having access to health services and social support.

While entire communities are impacted when exposed to man-made or natural disasters, children are particularly affected (Balbus \& Malina, 2009; Peek, 2008; Shaw et al., 2012). Children and youth are vulnerable to a disaster's effects, often because of their limited ability to be independent compared to adults, and their limited ability to access resources such as medical, social, and educational on their own, and their coping and cognitive capacities are still in development (Chrisman \& Dougherty, 2014). Previous research has identified several major factors that affect children's well-being during and in the aftermath of disasters such as economic exposure e.g. loss in household income, preexisting risks or cumulative stressors, e.g. those who have been through multiple traumatic events and, parental distress (Murray, 2011; Osofsky et al., 2016).

Gulf Coast communities and their children were likely physically affected by the oil spill and clean-up operations through direct physical contact with the oil, tar balls or dispersants, through consumption of contaminated food and water, or through the inhalation of the volatile chemicals in their environment (Goldstein et al., 2011; Murray, 2011). However, the children and their families along the Gulf Coast did not only experience physical and environmental exposure to the oil spill but were also exposed to the economic effects of the spill (Abramson et al., 2013; Grattan et al., 2011). Children's health also likely suffered when their family lost their jobs or incomes as the DHOS had adversely impacted the Gulf Coast industries, such as fishing, seafood and tourism, that support the livelihoods of the communities. Children and youth were also exposed to the oil spill while engaging in activities related to their recreation environment e.g. playing on the beach, hunting, fishing or swimming or participating in oil cleanup activities (Abramson et al., 2013).

Understanding the association between children's physical and mental health symptoms and exposure to the DHOS is critical to public health assessments, and recovery planning. Concurrent life events, and predisposing factors such as personal characteristics which may be positive (protective factors) or negative (risk factors), can contribute to the effects of health problems or disorders that are produced by the primary or secondary stressors (Figure 1). Additionally, the absence or presence of moderating factors, such as parental education, educational achievement, socio-economic status, access to supportive resources and environment within which the children live, can influence the recovery trajectories of children affected by a disaster (Pfefferbaum et al., 2015). 


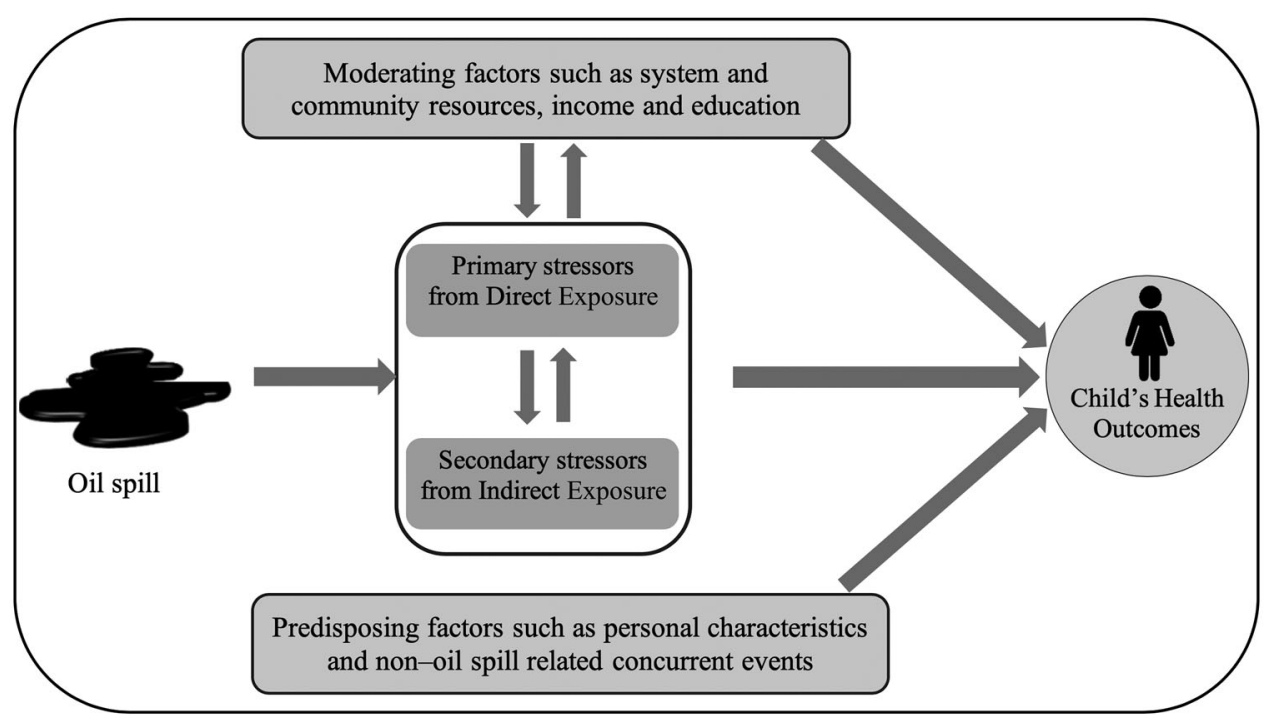

Figure 1. Conceptual pathway: Oil spill disaster, direct and indirect exposures and child's health outcomes (Source: Jaishree Beedasy).

\subsection{Study objective}

The main objective of this paper is to characterise the association of physical and mental health symptoms of children and their exposure to the DHOS along the harder-hit areas of the Gulf Coast, specifically in coastal Louisiana. The study focuses on the relationships between a number of specific exposure measures and the child's mental and physical health outcomes. In this study exposure is defined and measured as (i) the direct/ primary exposure i.e. direct physical contact with oil, tar and oil spill clean-up agents, smelling of oil and (ii) indirect/secondary exposure i.e. economically impacted through household income and job losses.

\section{Methodology}

\subsection{Prior work}

The study described in this paper is informed by a previous cross-sectional study conducted in 2012 by researchers at the National Center for Disaster Preparedness, Columbia University. A household survey had been completed in highly impacted areas of Louisiana, Mississippi, Alabama, and Florida and $18 \%$ of the parents had reported that their children had direct contact with the oil (Abramson et al., 2013). More than $40 \%$ had said that their children had experienced some type of mental or physical health symptoms since the oil spill (Abramson et al., 2013).

In 2014, the interviewers returned to the hard-hit areas in Louisiana, one of the four Gulf Coast states where they had previously conducted the 2012 household survey, to collect data. These data were used to get a deeper understanding of the persisting children's health issues and their associations with oil exposure. 


\subsection{Study population, sampling and data collection}

The recruitment of respondents into the 2014 study was based on the 2012 survey sampling frame. A multi-stage sampling design had been used to select zip codes, census blocks and households with children. Zip codes were used as proxies for neighbourhoods or geographic communities. To identify communities which were highly impacted, a proxy measure of oil impact was created. The development of the oil impact index was based on (1) individual claims data obtained from the Gulf Coast Claims Facility (GCCF), (2) business claims data from GCCF, and (3) the oiling data from geographic points along the Gulf Coast from the National Oceanic and Atmospheric Administration's (NOAA's) Shoreline Cleanup and Assessment Technique (SCAT) dataset. Statistical z-scores, standardised dimensionless values, were calculated for each community (zip code), for each of the three pieces of secondary data, individual claims $\left(z_{i c}\right)$, business claims $\left(z_{b c}\right)$, and the NOAA aggregated oiling $\operatorname{scores}\left(z_{o s}\right)$. The three $z$-scores were summed to create an overall oil impact index for each community, $z_{i d x}=z_{i c}+z_{b c}+z_{o s}$. Figure 2 shows the overall oil impact index along the coast of Louisiana. The coastal zip codes were rank ordered using the overall oil impact scores and the top-ranking zip codes were chosen. Within these highly impacted communities, a two-stage cluster design was used to select a random sample of census blocks and within each census block, households with children.

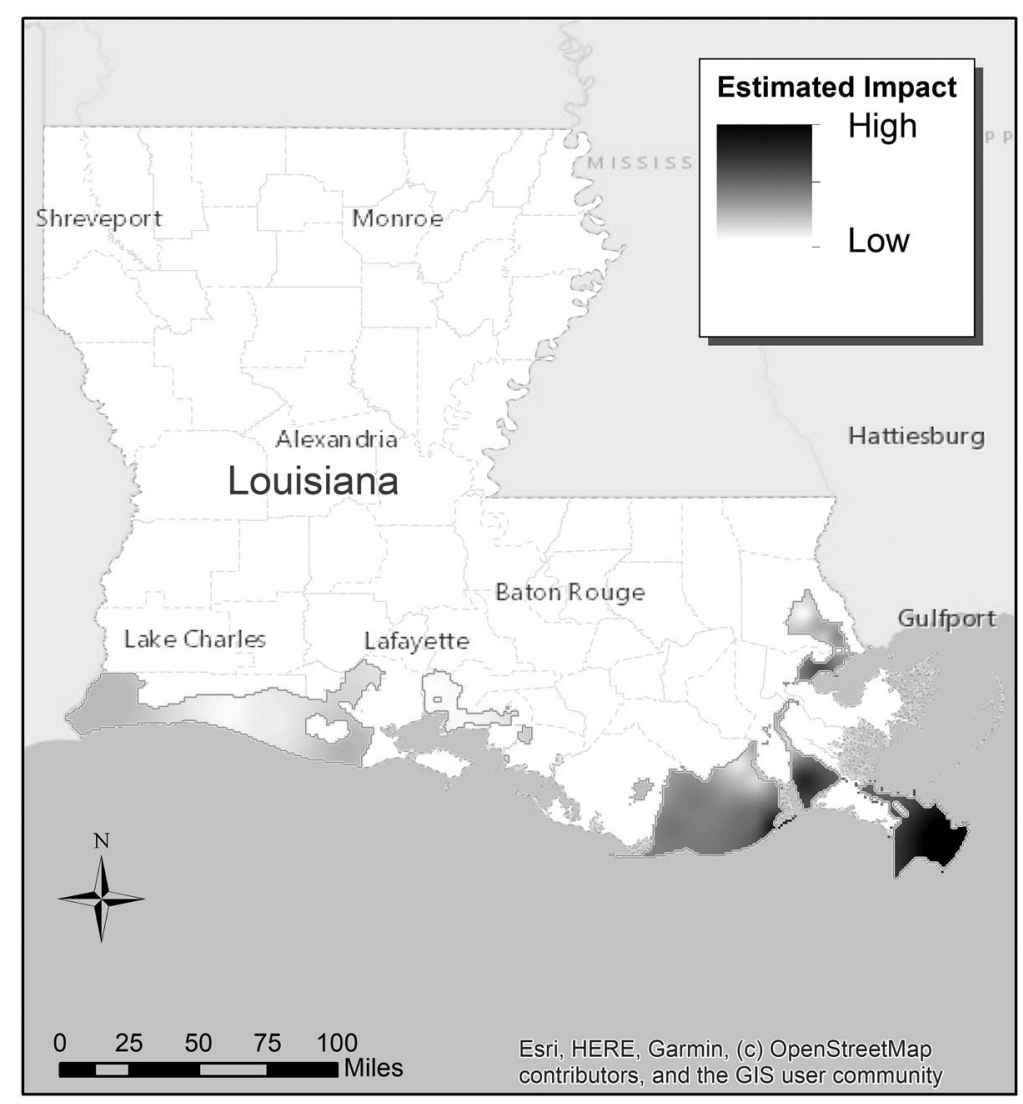

Figure 2. Overall oil impact index along coastal Louisiana. 
For each community, 10-20 census blocks were selected proportional to the size of the community, with size being determined by the number of blocks having households with children. Census blocks were selected for inclusion only if they had at least 5 households with children and at least 70\% occupancy, according to 2010 US Census data.

A two-armed protocol was used in the random sampling of households. If a selected census block had less than or equal to 40 households according to 2010 US Census data, then every household was approached to determine eligibility. For a block with more than 40 occupied households, every household from a list of household addresses with children purchased from InfoUSA ${ }^{\circledast}$ was approached. To mitigate the potential bias in the purchased list, (1) the adjacent households to the left and right of the household were also approached, and (2) a 1:1 matching household was selected within the census block based on random points, i.e. points generated by a GIS software, and the random point address and adjacent households on either side were also approached.

From April through August 2014 field interviewers surveyed households in coastal Louisiana. They interviewed parents living in Lafourche, Jefferson, Orleans, Plaquemines, St. Tammany, Terrebonne, and Vermillion parishes where the highly impacted communities had been identified using the overall oil impact index. The survey data was collected using a tablet-based computer-assisted personal interview (CAPI) system. Once an adult household member was identified, screening questions were asked in order to determine eligibility. The inclusion criteria were (1) the consenting adult (parent, guardian, or caregiver of the child) was 18 years of age or older, (2) there was a child residing in the household between the ages of 4 and 18, (3) both the adult and the child had lived in the zip code of the current address at the time of the oil spill. In households with more than one child, a last birthday subject sampling strategy (Binson et al., 2000; O'Rourke \& Blair, 1983) was adopted to choose the child whose health and well-being the parent would report on. The interview duration was between 15 to 20 minutes. A total of 720 interviews were completed. The data collection and study procedures were approved by Columbia University's Institutional Review Board.

\subsection{Analysis}

The survey instrument covered several thematic areas including direct and indirect exposure to the oil spill, physical and mental health status, sense of community, income and job losses, perceived recovery, and background demographic characteristics such as race, age, education level, and gender were also collected.

Of the 720 respondents, $56.9 \%$ were white, $27.2 \%$ were black, $4.2 \%$ were Asian and $3.1 \%$ were Native American/Alaskan and the rest were either mixed or another race. $79.7 \%$ of the respondents had less than a college degree and $54.7 \%$ of the participants' household annual income was below or equal to $\$ 70,000$, although more than a quarter $(26.7 \%)$ of the respondents said they did not know or refused to report their incomes.

The outcome variables for the study were formulated from a series of questions from the survey regarding the child's health status. A child was considered to have physical health issues that could potentially be related to the oil spill if a parent reported that at any time since the oil spill, the child had at least one of the five surveyed physical 
health problems - respiratory symptoms, vision problems, skin problems, headaches, and unusual bleeding. Similarly, a child was considered to have experienced mental health issues that could potentially be related to the oil spill if at least one of the four mental health questions, being depressed or very sad, feeling nervous or afraid, having sleeping problems, or having problems getting along with other children, was answered with a yes. The four mental health questions and the respiratory vision, skin, headaches questions were adapted from the Community Assessment for Public Health Emergency Response (CASPER) in Alabama and Mississippi following the oil spill (Buttke et al., 2012). The CASPER surveys had been developed by the Centers for Disease Control and Prevention (CDC) in coordination with the local health departments (Buttke et al., 2010).

Two types of exposure were defined based on the parent's report. Direct exposure variables were defined as the child having come into direct physical contact with the oil, tar and oil spill clean-up agents, the adult being exposed to oil smells and the adult coming into physical contact with the oil or tar. Indirect exposure variables were defined as the household having experienced an income loss and the household having suffered a job loss as a result of the oil spill.

As described earlier, the health outcomes were binary, and a series of logistic regressions was carried out to analyse the relationship between the children's physical and mental health outcomes and the different exposure variables.

\section{Results}

\subsection{Overview of health outcome and exposure variables}

$60.4 \%$ of the parents reported that their child had experienced physical health symptoms since the oil spill. $30.1 \%$ said their child had mental health issues post oil spill. $11.9 \%$ of the children and $20.8 \%$ of the adults had experienced direct physical contact with oil, tar or dispersant, $36.3 \%$ had been exposed to the smell of oil spill, $33.8 \%$ of the households had suffered income losses and $12.8 \%$ had experienced job loss.

\subsection{Children's physical health outcomes}

The odds ratios (ORs) resulting from the logistic regressions on the children's physical health outcome variable are displayed in Table 1. The ORs for all the different exposures are significantly larger than one. This implies that when a parent reports that exposure to the oil spill occurred, they are significantly more likely to also report a physical health issue for their child.

Children who were reported to be directly exposed to oil, had odds of physical health problems that were more than four times higher than those who were not exposed $(\mathrm{OR}=$ 4.14, 95\% Cl 2.29-7.51). Children whose parents that had been physically exposed, had nearly three times higher odds $(\mathrm{OR}=2.94,95 \% \mathrm{Cl} 1.93-4.48)$ of reported physical health problems. Parental exposure to oil smell was linked to more than four and a half times the odds $(\mathrm{OR}=4.59,95 \% \mathrm{Cl} 3.21-6.56)$ of the child experiencing a physical health issue. Children living in households that had indicated income losses were nearly three times $(\mathrm{OR}=2.88,95 \% \mathrm{Cl} 2.04-4.07)$ as likely to have experienced physical health impacts 
Table 1. The unadjusted odds ratios from logistic regressions on children's physical health outcomes following the DHOS as reported by parents. Each row represents a separate logistic regression.

\begin{tabular}{|c|c|c|c|c|}
\hline \multirow{2}{*}{$\begin{array}{l}\text { Variable } \\
\text { Exposure variables }\end{array}$} & \multirow[t]{2}{*}{$\mathrm{OR}$} & \multirow[t]{2}{*}{ S.E. } & \multicolumn{2}{|c|}{$[95 \% \mathrm{Cl}]$} \\
\hline & & & & \\
\hline Direct Physical Exposure (child) - Yes vs No & $4.14^{* * *}$ & 1.26 & 2.29 & 7.51 \\
\hline Direct Physical Exposure (parent) - Yes vs No & $2.94^{* * *}$ & 0.63 & 1.93 & 4.48 \\
\hline Exposure by smell - Yes vs No & $4.59^{* * *}$ & 0.84 & 3.21 & 6.56 \\
\hline Income loss - Yes vs No & $2.88^{* * *}$ & 0.51 & 2.04 & 4.07 \\
\hline Job loss - Yes vs No & $2.81^{* * *}$ & 0.76 & 1.66 & 4.77 \\
\hline \multicolumn{5}{|l|}{ Other variables } \\
\hline Education - College degree vs no college degree & $0.55^{* *}$ & 0.10 & 0.38 & 0.79 \\
\hline Race - White vs non-white & $0.59^{* *}$ & 0.09 & 0.44 & 0.81 \\
\hline Income $>\$ 70,000$ vs $<=\$ 70,000$ & $0.64^{*}$ & 0.12 & 0.44 & 0.93 \\
\hline Child Gender Female vs Male & 0.96 & 0.15 & 0.71 & 1.29 \\
\hline Child under 6 years vs older & 0.80 & 0.19 & 0.50 & 1.29 \\
\hline
\end{tabular}

Notes: Each row represents a separate logistic regression. $\mathrm{OR}=$ odds ratio, $p=p$-value, S.E. $=$ standard error, $\mathrm{Cl}=$ confidence interval.

${ }^{*} p<.05$

${ }^{* *} p<.01$

*** $p<.001$

compared to households with no reported income loss. Reported job loss was associated to nearly 3 times higher odds of children's physical health problems $(\mathrm{OR}=2.81,95 \% \mathrm{Cl}$ 1.66-4.77).

Besides the exposure factors, the education, race, and income variables in Table 1 may be mitigating or aggravating factors for children's physical health issues. Race was analysed by comparing adults who reported being white and those who reported not being white. Education level was analysed by considering whether the adult had at least a college degree or not. Income was divided into households with an annual income greater than $\$ 70,000$ and those with an income equal to or less than $\$ 70,000$. Parents that had at least a college degree $(\mathrm{OR}=0.55,95 \% \mathrm{Cl} 0.38-0.79)$, or that self-identified as white $(\mathrm{OR}=0.59,95 \% \mathrm{Cl} 0.44-0.81)$, or when the annual household income was greater than $\$ 70,000(\mathrm{OR}=0.64,95 \% \mathrm{Cl} 0.44-0.93)$, were significantly less likely to report physical health issues for their children. The child's gender does not seem to be associated with a significant difference in the reported physical health outcome. Additionally, the results did not indicate statistically significant differences between children less than 6 years when compared to those 6 years or older.

Table 2 provides results of logistic regression analyses where additionally to the exposure variable, the education and race variables are included as controls. Since more than a quarter of the respondents did not answer the income question, income was not used as a control variable. Using the income variable would strongly reduce the number of observations and is therefore not considered to be reliable. It is known that income data are both difficult to collect and subject to non-reporting. Education is one of the most commonly measured indicators of socioeconomic position given that it is subject to little misclassification, and credentials are often the means to advancement (National Research Council, 2004). Education is correlated with income and can, therefore, be considered as a proxy for income levels. This adjusted model shows very similar ORs as in Table 1. The results are therefore robust to adjusting for race and education level. This adjusted model shows that both direct and indirect exposure are related to significantly greater odds of a child experiencing adverse physical health symptoms. 
Table 2. The odds ratios from logistic regressions on children's physical health outcomes following the DHOS as reported by parents. Each row represents a separate logistic regression that is adjusted for parent's education level and race.

\begin{tabular}{|c|c|c|c|c|}
\hline Variable & OR & S.E. & \multicolumn{2}{|c|}{$[95 \% \mathrm{Cl}]$} \\
\hline Direct Physical Exposure (child) - Yes vs No & $4.56^{* * *}$ & 1.40 & 2.49 & 8.34 \\
\hline Direct Physical Exposure (parent) - Yes vs No & $3.11^{* * *}$ & 0.68 & 2.03 & 4.79 \\
\hline Exposure by smell - Yes vs No & $4.44^{* * *}$ & 0.82 & 3.10 & 6.37 \\
\hline Income loss - Yes vs No & $2.74^{* * *}$ & 0.49 & 1.93 & 3.90 \\
\hline Job loss - Yes vs No & $2.65^{* * *}$ & 0.73 & 1.55 & 4.54 \\
\hline
\end{tabular}

Notes: Each row represents a separate logistic regression that is adjusted for parent's education level and race. OR $=$ odds ratio, $p=p$-value, S.E. $=$ standard error, $\mathrm{Cl}=$ confidence interval.

${ }^{*} p<.05$

${ }^{* *} p<.01$

${ }^{* * *} p<.001$

\subsection{Children's mental health outcomes}

Similar to the physical health outcomes, both direct and indirect exposures were linked to higher odds of developing adverse mental health outcomes. Table 3 provides the ORs of the regression analysis for the children's mental health outcomes. Again, all the different exposure variables have ORs that are significantly larger than one. The direct physical exposure of the child to the oil shows the highest odds of having mental health issues $(\mathrm{OR}=4.64,95 \% \mathrm{Cl} 2.90-7.42)$. A parent that reported direct physical exposure to the oil spill was nearly two and a half times more likely $(\mathrm{OR}=2.58,95 \% \mathrm{Cl} 0.49-1.77)$ to report a mental health issue for their child compared to a parent who did not. The odds of reported mental health outcomes through exposure by smell $(\mathrm{OR}=3.31,95 \% \mathrm{Cl} 2.35-4.67)$ was 3 times more compared to those who were not exposed. Household income loss (OR= $3.22,95 \% \mathrm{Cl} 2.31-4.67)$ and family job loss $(\mathrm{OR}=3.28,95 \% \mathrm{Cl} 2.10-5.13)$ were all associated with more than 3 times the likelihood of children having adverse mental health effects. The income and job loss related exposure variables have higher ORs than those for the physical health outcomes. This suggests that the indirect economic exposure may have an even larger adverse effect on the mental health than on the physical health of the children.

Table 3. The odds ratios from logistic regressions on children's mental health outcomes following the DHOS as reported by parents. Each row represents a separate logistic regression.

\begin{tabular}{|c|c|c|c|c|}
\hline \multirow{2}{*}{$\begin{array}{l}\text { Variable } \\
\text { Exposure variables }\end{array}$} & \multirow[t]{2}{*}{ OR } & \multirow[t]{2}{*}{ S.E. } & \multicolumn{2}{|c|}{$[95 \% \mathrm{Cl}]$} \\
\hline & & & & \\
\hline Direct Physical Exposure (child) - Yes vs No & $4.64^{* * *}$ & 1.11 & 2.9 & 7.42 \\
\hline Direct Physical Exposure (parent) - Yes vs No & $2.58^{* * *}$ & 0.49 & 1.77 & 3.75 \\
\hline Exposure by smell - Yes vs No & $3.31^{* * *}$ & 0.58 & 2.35 & 4.67 \\
\hline Income loss - Yes vs No & $3.22^{* * *}$ & 0.55 & 2.31 & 4.50 \\
\hline Job loss - Yes vs No & $3.28 * * *$ & 0.75 & 2.10 & 5.13 \\
\hline \multicolumn{5}{|l|}{ Other variables } \\
\hline Education - College degree vs no college degree & $0.53^{* *}$ & 0.12 & 0.34 & 0.83 \\
\hline Race - White vs non-white & 0.84 & 0.14 & 0.61 & 1.16 \\
\hline Income $>\$ 70,000$ vs $<=\$ 70,000$ & 0.75 & 0.16 & 0.49 & 1.15 \\
\hline Child Gender Female vs Male & 0.94 & 0.16 & 0.68 & 1.30 \\
\hline Child under 6 years vs older & 0.60 & 0.17 & 0.34 & 1.06 \\
\hline
\end{tabular}

Notes: Each row represents a separate logistic regression. $\mathrm{OR}=$ odds ratio, $p=p$-value, S.E. $=$ standard error, $\mathrm{Cl}=$ confidence interval.

${ }^{*} p<.05$

${ }^{* *} p<.01$

*** $p<.001$ 
The education variable has an odds ratio under one $(\mathrm{OR}=0.53,95 \% \mathrm{Cl} 0.34-0.83)$, i.e. the likelihood of parents who had a college degree reporting adverse mental health effects for their children were significantly less than those who did not have a college degree. On the other hand, while the OR is less than one for the race variable, it is not significant. There can be several reasons for this, including that firstly, our measures of mental and physical wellbeing are parental reports, and reporting mental health issues for their children might be less of a stigma among white people compared to other communities. Mental health issues among children of non-white respondent could have been underreported in the data. Or, it could be that white children might be more susceptible to mental health issues. However, such racial/ethnic differences for mental health outcomes are very difficult to measure. There have been inconsistent findings linking race/ethnicity with mental illness, with some studies indicating poorer mental health among racial and ethnic minorities relative to whites, while others reporting no differences or better psychological health among minorities (Adams \& Boscarino, 2005). While the odds ratio is less than 1 for annual household income greater than $\$ 70,000$, this finding, unlike the results for the physical health outcome, is not statistically significant. However, as discussed earlier, more than $25 \%$ of the respondents did not answer the income question income, and hence the income variable may not be reliable. The child's gender (female vs male) or, the child's age ( $<6$ years vs $\geq 6$ years), were not associated with a significant difference in the reported mental health outcome.

Finally, we also considered the adjusted model for the mental health outcomes in Table 4. The results are again robust to adjusting for race and education of the parent. They reveal that both direct and indirect exposures to the oil spill are associated with greater likelihoods of the child experiencing negative mental health challenges.

Table 4. The odds ratios from logistic regressions on children's mental health outcomes following the DHOS as reported by parents. Each row represents a separate logistic regression that is adjusted for parent's education level and race.

\begin{tabular}{lcccr}
\hline Variable & OR & S.E. & {$[95 \% \mathrm{Cl}]$} \\
\hline Direct Physical Exposure (child) - Yes vs No & $4.79^{* * *}$ & 1.17 & 2.97 & 7.74 \\
Direct Physical Exposure (parent) - Yes vs No & $2.58^{* * *}$ & 0.50 & 1.76 & 3.77 \\
Exposure by smell - Yes vs No & $3.24^{* * *}$ & 0.57 & 2.29 & 4.58 \\
Income loss - Yes vs No & $3.05^{* * *}$ & 0.53 & 2.17 & 4.28 \\
Job loss - Yes vs No & $3.07^{* * *}$ & 0.71 & 1.96 & 4.82 \\
\hline
\end{tabular}

Notes: Each row represents a separate logistic regression that is adjusted for parent's education level and race. OR $=$ odds ratio, $p=p$-value, S.E. $=$ standard error, $\mathrm{Cl}=$ confidence interval.

${ }^{*} p<.05$

${ }^{* *} p<.01$

${ }^{* * *} p<.001$

\section{Discussion}

Our findings suggest that Gulf Coast children who were reportedly exposed to the oil spill by direct physical contact or through economic loss had significantly greater likelihood of experiencing physical and mental health symptoms than those who were not exposed. While indirect exposure, i.e. household income or job loss, may not be as concrete or palpable as the primary stressors, such as coming into direct contact with the oil, tar or dispersants, our results show that these secondary stressors are also strongly associated with the physical health of the children and to a slightly higher degree with their mental health 
outcomes. Acute toxic effects are linked with direct exposure to oil and oil dispersants and oil burned in situ and, depending on the duration and intensity levels, exposure to oil has the potential to cause a large set of health symptoms including ocular problems such as soreness, itching of the eyes, respiratory symptoms such as shortness of breath, wheezing, and neurological symptoms such as headache and dizziness (Institute of Medicine, 2010). Dermal contact with the oil or tar causes toxic health effects such as symptoms of the skin and mucous membranes including irritation, rash and blisters (Institute of Medicine, 2010). When oil is burned in situ or evaporates, a small, though significant, portion is converted into very small aerosol particles and exposure to fine particulate air pollution has adverse effects on cardiopulmonary health (Middlebrook et al., 2012; Pope \& Dockery, 2006).

In this study, direct exposure to the DHOS was found to be associated with physical and mental health issues in children and, is consistent with our prior initial observations in children in highly oil spill-impacted regions in the Gulf Coast (Abramson et al., 2013). Other DHOS studies have reported similar impacts of direct exposure in women (Peres et al., 2016) and in oil spill clean-up workers (D'andrea \& Reddy, 2013). Similarly, higher negative physical health outcomes have been reported in those directly exposed during the EVOS (Palinkas, 2012, 1993). Our findings also indicate that indirect exposures such as household income and job loss were associated with increased negative physical and mental health outcomes in children and adolescents. This may be a consequence of stress caused by the economic burden on the family though the causal mechanism is not always well known (Nichols et al., 2013). Furthermore, associations between psychological stress and depression, viral infections, upper respiratory tract infections, and asthma have been documented in the literature (Cohen et al., 2007; Irwin, 2008). Based on the analysis of data from Medical Expenditure Panel Survey (MEPS), maintained by the Agency for Healthcare Research and Quality, Schaller and Zerpa (2019) observe that there is a deterioration in children's health and mental health when there is parental job loss especially in families with low socio-economic status. Parental job loss can also cause a reduction in children's well-being based partly on factors like reduced food, health and other expenditure, and deterioration of parents' physical and mental health, and tensions among family members and parent-child relationships (Kalil, 2005). Although less is known about the economic impact of the oil spill on children, it has been reported that adults who suffered DHOS related income losses reported higher mental health issues than those who did not (Grattan et al., 2011). Studies on the EVOS have shown association between economic loss and mental health symptoms (Arata et al., 2000) and that there are higher rates of depression and other mental health issues in those exposed and that there is long term prevalence of psychological, economic and social consequences on children, and families (Gill et al., 2012; Palinkas et al., 1993). One of the very few studies (Osofsky et al., 2016) evaluating the mental health of children before and after the DHOS, reports that the exposure of children and their families to the oil spill's economic and ecological consequences can extend to the mental health problems of children and youth. Our findings serve to substantiate studies on the physical and mental health impact of oil spill disasters and augment the limited literature on the effects of the DHOS, particularly on children and youth. Our findings additionally highlight the role of parental educational attainment, an important indicator of socio-economic status, as a predictor of both physical and mental health of children. The importance of race, families' 
income, and the education level of parents on children's health outcomes has been reported in the literature (Chen et al., 2006; Williams et al., 2016).

The study has several limitations that need to be considered when interpreting the presented findings. Given that the survey was conducted with parents or caregivers of children four years after the oil spill, information loss and recall bias cannot be excluded. The exposure data and child health symptoms are based on parental reports. Previous research has demonstrated that parent-reported data are subject to both under and over-reporting (Achenbach, 2011; Kim et al., 2016). In addition, it is possible that those who were exposed to oil from the spill may have had a better recollection than those who were not exposed, and mental health outcomes may have been underreported because of fear of stigma. To minimise some of these biases interviewers were trained to be objective recorders of each respondent's experiences to avoid interviewer bias, i.e. not influencing the survey responses in any way. The interviewers were also trained to facilitate recall by adopting time structuring techniques to help respondents recollect when an event occurred to retrieve the required information. Given that the study was conducted a few years after the DHOS, some families might very likely have moved during that period for various reasons - economic, health or psychological reasons, or to get a fresh start. The latter were therefore not interviewed causing an underrepresentation of oil spill affected children from this group.

Findings from this study can only suggest that there are associations between children's health problems and the oil spill. Direct causality of the health effects cannot be attributed to the oil spill because of lack of pre-oil spill data, our cross-sectional approach, and also given that children's health and well-being are determined by the interaction of a multitude of influences including their developmental level, availability of health and socio-economic resources, previous trauma exposure such as assault or abuse, pre-existing child and family issues, and family and community characteristics. The study design does not allow the investigation of the detailed pathways and mechanisms of how all the different secondary stressors can affect the child's outcomes. For example, parental post-disaster psychopathology, which was not assessed, can be a possible contributor to children's post-disaster behavioural and emotional problems, and may also bias parental report of child's health and behaviour (Boer et al., 2009; Gewirtz et al., 2008; Kiliç et al., 2003; North et al., 2018). Furthermore, the study did not collect how much income or what proportion of the total household income was lost. This limited the authors from examining the impact that the loss may have caused depending on the income level of the household.

By adopting a longitudinal approach, the impact of some confounding can be reduced. The cohort of respondents from this study is currently being followed up with two additional waves of interviews. Despite the aforementioned limitations, the study makes an important contribution to the scarce literature on the health effects of the DHOS on the children and youth living along the Gulf Coast.

\subsection{Conclusion and Implication}

The study has shown that children are vulnerable to not only direct physical exposure, but to secondary stressors resulting from economic losses in the family. More attention should be focused on the different types of exposures and associated stressors that impact both mental and physical well-being of affected communities, in particular, children and youth. This is particularly important as the secondary stressors tend to persist for longer periods 
of time. Technological disasters, such as the DHOS, are slow and accompanied by uncertainty, and extended periods of uncertainty are detrimental to the health and well-being of children. Our findings contribute to bridge the research gap on the impacts of direct and indirect exposures of the DHOS on the health of children. Knowledge gained from this study together with the emerging literature on the effect of the DHOS disaster on children can contribute towards more evidence-based public health policies to similar disasters. The Gulf Coast is a uniquely vulnerable place, where liveability is affected by the increasing frequency and severity of natural disasters, technological accidents, and the socioeconomic vulnerability of the local communities. Hence the importance of promoting and providing preparedness resources, and culturally competent interventions cannot be neglected. In the future, it will be beneficial to adopt a community engaged research approach and promote the active participation of key stakeholders to enhance the disaster resilience of children and their families.

\section{Acknowledgements}

The authors thank Dr David Abramson at New York University as well as the Gulf Coast survey team, who had been part of the initial study, for their insights and expertise. The authors also express appreciation for the generous assistance provided by Jeremy Brooks at the National Center for Disaster Preparedness at Columbia University. The aforementioned may or may not agree with all of the interpretations or conclusions of this paper. The content is solely the responsibility of the authors and does not necessarily represent the official views of the funding organisation.

\section{Disclosure statement}

No potential conflict of interest was reported by the author(s).

\section{Funding}

This work was supported by the Baton Rouge Area Foundation [grant number PG005122 - BRAF CU13-0598].

\section{References}

Abramson, D. M., Peek, L., Redlener, I. E., Beedasy, J., Aguilar, T., Sury, J., Banister, A. N., \& May, R. (2013). Children's health after the oil spill: A four-state study findings from the Gulf Coast Population Impact (GCPI) project. Columbia University Academic Commons. https://doi.org/10. 7916/D8WQ0C4P

Achenbach, T. M. (2011). Commentary: Definitely more than measurement error: But How should we understand and deal with informant discrepancies? Journal of Clinical Child \& Adolescent Psychology, 40(1), 80-86. https://doi.org/10.1080/153744416.2011.533416

Adams, R. E., \& Boscarino, J. A. (2005). Differences in mental health outcomes among whites, African Americans, and Hispanics following a community disaster. Psychiatry, 68(3), 250-265. https://doi. org/10.1521/psyc.2005.68.3.250

Arata, C. M., Picou, J. S., Johnson, G. D., \& Mcnally, T. S. (2000). Coping with technological disaster: An application of the conservation of resources model to the Exxon Valdez Oil spill. Journal of Traumatic Stress, 13(1), 23-39. https://doi.org/10.1023/a:1007764729337

Arosemena, F. A., Fox, L., \& Lichtveld, M. Y. (2013). Reproductive health assessment after disasters: Embedding a toolkit within the disaster management workforce to address health inequalities 
among Gulf-Coast women. Journal of Health Care for the Poor and Underserved, 24(4A), 17-28. https://doi.org/10.1353/hpu.2014.0013

Balbus, J. M., \& Malina, C. (2009). Identifying vulnerable subpopulations for climate change health effects in the United States. Journal of Occupational and Environmental Medicine, 51(1), 33-37. https://doi.org/10.1097/JOM.0b013e318193e12e

Binson, D., Canchola, J. A., \& Catania, J. A. (2000). Random selection in a national telephone survey: A comparison of the Kish, next-birthday, and last-birthday methods. Journal Of Official StatisticsStockholm, 16, 53-60.

Boer, F., Smit, C., Morren, M., Roorda, J., \& Yzermans, J. (2009). Impact of a technological disaster on young children: A five-year postdisaster multiinformant study. Journal of Traumatic Stress: Official Publication of The International Society for Traumatic Stress Studies, 22(6), 516-524. https://doi.org/ 10.1002/jts.20461

Buttke, D., Vagi, S., Fleischer, N., Podgornik, M., Tara, S., Gould, D., Bell, J., \& Wolkin, A. (2010). Community Assessment for Public Health Emergency (CASPER) after the Gulf Coast oil spill: Alabama, 2010. Retrieved March 18, 2018, from http://www.adph.org/CEP/assets/CASPER_ report.pdf

Buttke, D., Vagi, S., Schnall, A., Bayleyegn, T., Morrison, M., Allen, M., \& Wolkin, A. (2012). Community Assessment for Public Health Emergency Response (CASPER) one year following the Gulf Coast oil spill: Alabama and Mississippi, 2011. Prehospital and Disaster Medicine, 27(6), 496-502. https://doi. org/10.1017/S1049023X12001380

Chen, E., Martin, A. D., \& Matthews, K. A. (2006). Understanding health Disparities: The role of race and socioeconomic status in children's health. American Journal of Public Health, 96(4), 702-708. https://doi.org/10.2105/ajph.2004.048124

Chrisman, A. K., \& Dougherty, J. G. (2014). Mass trauma: Disasters, terrorism, and war. Child and Adolescent Psychiatric Clinics of North America, 23(2), 257-279. https://doi.org/10.1016/j.chc.2013. 12.004

Cline, R. J., Orom, H., Berry-Bobovski, L., Hernandez, T., Black, C. B., Schwartz, A. G., \& Ruckdeschel, J. C. (2010). Community-level social support responses in a slow-motion technological disaster: The case of Libby, Montana. American Journal of Community Psychology, 46(1-2), 1-18. https://doi. org/10.1007/s10464-010-9329-6

Cohen, S., Janicki-Deverts, D., \& Miller, G. E. (2007). Psychological stress and disease. Jama, 298(14), 1685-1687. https://doi.org/10.1001/jama.298.14.1685

D'andrea, M. A., \& Reddy, G. K. (2013). Health consequences among subjects involved in Gulf oil spill clean-up activities. The American Journal of Medicine, 126(11), 966-974. https://doi.org/10.1016/j. amjmed.2013.05.014

DOI. (2010). U.S. scientific teams refine estimates of oil flow from BP's well prior to capping (Interior, U.S.D.O., Ed.). US DOI Press Office. http://www.doi.gov/news/pressreleases/US-Scientific-TeamsRefine-Estimates-of-Oil-Flow-from-BP-Well-Prior-to-Capping.cfm

Freudenburg, W. R. (1997). Contamination, corrosion and the social order: An overview. Current Sociology, 45(3), 19-39. https://doi.org/10.1177/001139297045003002

Gewirtz, A., Forgatch, M., \& Wieling, E. (2008). Parenting practices as potential mechanisms for child adjustment following mass trauma. Journal of Marital and Family Therapy, 34(2), 177-192. https:// doi.org/10.1111/j.1752-0606.2008.00063.x

Gill, D. A., Picou, J. S., \& Ritchie, L. A. (2012). The Exxon Valdez and BP oil spills: A comparison of initial social and psychological impacts. American Behavioral Scientist, 56(1), 3-23. https://doi.org/10. 1177/0002764211408585

Goldstein, B. D., Osofsky, H. J., \& Lichtveld, M. Y. (2011). The Gulf oil spill. The New England Journal of Medicine, 364(14), 1334-1348. https://doi.org/10.1056/NEJMra1007197

Grattan, L. M., Roberts, S., Mahan Jr, W. T., Mclaughlin, P. K., Otwell, W. S., \& Morris Jr, J. G. (2011). The early psychological impacts of the Deepwater Horizon oil spill on Florida and Alabama communities. Environmental Health Perspectives, 119(6), 838-843. https://doi.org/10.1289/ehp. 1002915

Institute of Medicine. (2010). Assessing the effects of the Gulf of Mexico oil spill on human health: A summary of the June 2010 Workshop. The National Academies Press. 
Irwin, M. R. (2008). Human psychoneuroimmunology: 20 years of discovery. Brain, Behavior, and Immunity, 22(2), 129-139. https://doi.org/10.1016/j.bbi.2007.07.013

Kalil, A. (2005). Unemployment and job displacement: The impact on families and children. Ivey Business Journal, 69, 1-5.

Kiliç, E. Z., Özgüven, H. D., \& Sayil, I. (2003). The psychological effects of parental mental health on children experiencing disaster: The experience of Bolu earthquake in Turkey. Family Process, 42 (4), 485-495. https://doi.org/10.1111/j.1545-5300.2003.00485.x

Kim, J., Chan, Y.-F., Mccauley, E., \& Stoep, A. V. (2016). Parent-Child Discrepancies in reporting of child depression in ethnic groups. The Journal for Nurse Practitioners: JNP, 12(6), 374-380. https://doi. org/10.1016/j.nurpra.2016.01.018

Kousky, C. (2016). Impacts of natural disasters on children. The Future of Children, 26(1), 73-92. https:// doi.org/10.1353/foc.2016.0004

Lock, S., Rubin, G. J., Murray, V., Rogers, M. B., Amlôt, R., \& Williams, R. (2012). Secondary stressors and extreme events and disasters: A systematic review of primary research from 2010-2011. PLoS Currents: Disasters, 4. https://doi.org/10.1371/currents.dis.a9b76fed1b2dd5c5bfcfc13c87a2f24f

Masten, A. S., \& Narayan, A. J. (2012). Child development in the context of disaster, war, and terrorism: Pathways of risk and resilience. Annual Review of Psychology, 63(1), 227-257. https://doi.org/10. 1146/annurev-psych-120710-100356

Mclees-Palinkas, T. L. (1994). Psychosocial impacts of disasters on families and children: The ExxonValdez oil spill. San Diego State University.

Middlebrook, A. M., Murphy, D. M., Ahmadov, R., Atlas, E. L., Bahreini, R., Blake, D. R., Brioude, J., De Gouw, J. A., Fehsenfeld, F. C., \& Frost, G. J. (2012). Air quality implications of the Deepwater Horizon oil spill. Proceedings of the National Academy of Sciences, 109(50), 20280-20285. https:// doi.org/10.1073/pnas.1110052108

Murray, J. S. (2011). The effects of the Gulf oil spill on children. Journal for Specialists in Pediatric Nursing, 16(1), 70-74. https://doi.org/10.1111/j.1744-6155.2010.00271.x

National Research Council. (2004). Recommendations on the use of socioeconomic position indicators to better understand racial inequalities in health. In Eliminating health disparities: Measurement and data needs (pp. 193-194). Washington, DC: The National Academies Press. https://doi.org/10.17226/10979

Nichols, A., Mitchell, J., \& Lindner, S. (2013). Consequences of long-term unemployment. The Urban Institute.

North, C. S., Mendoza, S., Simic, Z., \& Pfefferbaum, B. (2018). Parent-reported behavioral and emotional responses of children to disaster and parental psychopathology. Journal of Loss and Trauma, 23(4), 303-316. https://doi.org/10.1080/15325024.2018.1443710

O'rourke, D., \& Blair, J. (1983). Improving random respondent selection in telephone surveys. Journal of Marketing Research, 4(4), 428-432. https://doi.org/10.1177/002224378302000409

Osofsky, J. D., Osofsky, H. J., Weems, C. F., Hansel, T. C., \& King, L. S. (2016). Effects of stress related to the Gulf oil spill on child and adolescent mental health. Journal of Pediatric Psychology, 41(1), 6572. https://doi.org/10.1093/jpepsy/jsu085

Palinkas, L. A. (2012). A conceptual framework for understanding the mental health impacts of oil spills: Lessons from the Exxon Valdez oil spill. Psychiatry-Interpersonal and Biological Processes, 75(3), 203-222. https://doi.org/10.1521/psyc.2012.75.3.203

Palinkas, L. A., Petterson, J. S., Russell, J., \& Downs, M. A. (1993). Community patterns of psychiatricdisorders after the Exxon-Valdez oil-spill. American Journal of Psychiatry, 150(10), 1517-1523. https://doi.org/10.1176/ajp.150.10.1517

Palinkas, L. A., Russell, J., Downs, M. A., \& Petterson, J. S. (1992). Ethnic differences in stress, coping, and depressive symptoms after the Exxon Valdez oil spill. Journal of Nervous and Mental Disease, 180(5), 287-295. https://doi.org/10.1097/00005053-199205000-00002

Peek, L. (2008). Children and disasters: Understanding vulnerability, developing capacities, and promoting resilience-An introduction. Children Youth and Environments, 18, 1-29.

Peres, L. C., Trapido, E., Rung, A. L., Harrington, D. J., Oral, E., Fang, Z., Fontham, E., \& Peters, E. S. (2016). The Deepwater Horizon oil spill and physical health among adult women in Southern Louisiana: 
The women and their children's health (WaTCH) study. Environmental Health Perspectives, 124(8), 1208-1213. https://doi.org/10.1289/ehp.1510348

Petkova, E. P., Beedasy, J., Oh, E. J., Sury, J. J., Sehnert, E. M., Tsai, W.-Y., \& Reilly, M. J. (2017). Long-term recovery from Hurricane Sandy: Evidence from a survey in New York City. Disaster Medicine and Public Health Preparedness, 12, 1-4. https://doi.org/10.1017/dmp.2017.57

Pfefferbaum, B., Jacobs, A. K., Houston, J. B., \& Griffin, N. (2015). Children's disaster reactions: The influence of family and social factors. Current Psychiatry Reports, 17(57), 1-6. https://doi.org/10. 1007/s11920-015-0597-6

Pope, C. A., \& Dockery, D. W. (2006). Health effects of fine particulate air pollution: Lines that connect. Journal of the Air \& Waste Management Association, 56(6), 709-742. https://doi.org/10.1080/ 10473289.2006.10464485

Ritchie, L. A., Gill, D. A., \& Picou, J. S. (2011). The BP disaster as an Exxon Valdez Rerun contexts. Sage.

Schaller, J., \& Zerpa, M. (2019). Short-run effects of parental job loss on child health. American Journal of Health Economics, 5(1), 8-41. https://doi.org/10.1162/ajhe_a_00106.

Shaw, J. A., Espinel, Z., \& Shultz, J. M. (2012). Care of children exposed to the traumatic effects of disaster. American Psychiatric Pub.

Shultz, J. M., Espinel, Z., Galea, S., \& Reissman, D. B. (2007). Disaster ecology: Implications for disaster psychiatry. In R. J. Ursano, C. S. Fullerton, L. Weisaeth, \& B. Raphael (Eds.), Textbook of disaster psychiatry (pp. 69-96).https://doi.org/10.1017/CBO9780511544415.005

Williams, D. R., Priest, N., \& Anderson, N. B. (2016). Understanding associations among race, socioeconomic status, and health: Patterns and prospects. Health Psychology: Official Journal of the Division of Health Psychology, American Psychological Association, 35(4), 407-411. https://doi.org/ $10.1037 /$ hea0000242 